\title{
Charge-Separation Reactions of Doubly-Protonated Peptides: Effect of Peptide Chain Length
}

\author{
Alex G. Harrison \\ Department of Chemistry, University of Toronto, Toronto, Ontario, Canada
}

The collision induced dissociation of doubly-protonated (Ala) xis $_{\mathrm{x}}(\mathrm{x}=5,6,7,8,10)$ peptides have been studied. The major fragmentation reactions observed are symmetrical amide bond cleavages to give the complementary $b_{m}$ and $y_{N-m}$ ions, where $N$ is the total number of residues in the peptide. Minor asymmetric cleavage to give doubly-protonated $\mathrm{y}$ ions also is observed, involving cleavage near the N-terminus. The shorter peptides $(\mathrm{x}=$ $5,6,7)$ show major cleavage of the second amide bond to yield $b_{2}$ and $y_{N-2}$ ions, while (Ala) ${ }_{10}$ His shows major symmetrical cleavage at the fourth and fifth amide bonds. (Ala) ${ }_{8}$ His appears to be a transitional peptide in showing substantial symmetrical cleavage at the second, fourth, and fifth amide bonds. The results are in general agreement with the bifurcating nature of charge separation noted by Zubarev (J. Am. Soc. Mass Spectrom. 2008, $19,1755-1763$ ) from a statistical analysis of a large body of doubly-protonated tryptic peptide CID mass spectra. It is shown that the $b_{2}$ ion derived from doubly-protonated (Ala) ${ }_{5}$ His has a protonated oxazolone structure. (J Am Soc Mass Spectrom 2009, 20, 1890-1895) (C) 2009 American Society for Mass Spectrometry

$\mathrm{T}$ landem mass spectrometry has become a widely used method for deriving sequence information for peptides and proteins [1-3]. Protein identification in the field of proteomics most often involves protein digestion by trypsin, with identification and sequencing of the peptides produced by collision-induced dissociation of the singly- or multiply-protonated peptides resulting from soft ionization methods such as electrospray ionization [4]. Trypsin usually cleaves proteins C-terminal to arginine or lysine with the result that the peptides produced have a highly basic residue at the C-terminus. Such basic residues will localize a proton on the basic side chain [5], which often leads to fragmentation associated with the basic site rather than cleavage along the peptide backbone that is necessary for peptide sequencing. As a consequence fragmentation of doubly- or multiply-charged peptides in which there is a mobile proton [5] has been found to provide more complete sequence information.

There have been many detailed studies of the dissociation chemistry of singly-protonated nontryptic peptides; these studies have been summarized in a recent review [6]. On the other hand, despite the importance of the fragmentation chemistry of doubly-protonated tryptic peptides in proteomics, much less is known in detail concerning the fragmentation reactions of such species. A common fragmentation reaction of doubly-

Address reprint requests to Dr. A. G. Harrison, Department of Chemistry, University of Toronto, 80 St. George Street, Toronto, ON M5S 3H6, Canada, E-mail: aharriso@chem.utoronto.ca protonated peptides is charge separation in which amide bond cleavage leads to complementary singlycharged $b$ and $y$ ions [7-10]. Recently, Zubarev and coworkers [11] have carried out a statistical analysis of a large database of CID spectra of doubly-protonated tryptic peptides. They found that the charge separation spectra fell into two well separated statistical classes. Class I CID spectra were dominated by the $\mathrm{y}_{\mathrm{N}-2}$ ion signal (and, presumably, the corresponding $b_{2}$ ion) where $\mathrm{N}$ is the number of amino acid residues in the peptide. By contrast, Class II CID spectra showed other $\mathrm{y}$ ions as the most abundant charge-separation products. There is some evidence from their analysis that cleavage of the second amide bond to form $\mathrm{y}_{\mathrm{N}-2}$ is particularly important for smaller peptides and decreases in relative importance with increasing size of the peptide. It appeared of interest to study a series of peptides where the only variable is the number of residues in the peptide so that the effect of chain length can be separated from other variables. Accordingly, we have studied the fragmentation reactions of a series of doubly-protonated peptides containing a variable number of alanine residues, in each case terminating with a histidine residue at the C-terminus. Although these are not tryptic peptides, one can reasonably expect that one proton will be localized on the basic histidine side chain with the second proton being mobile along the alanine chain. It has been shown [3] that doubly-protonated peptides with His at the C-terminus fragment in the manner typical of doubly-protonated tryptic peptides. The calculations of Bleiholder et al. [12] show that 
histidine is the third most basic amino acid and that the imidazole side chain has a proton affinity almost the same as the amino group of the acid.

\section{Experimental}

All experimental work was carried out using electrospray/quadrupole/time-of-flight (QqTOF) mass spectrometers (Ultima III; Waters/Micromass, Manchester, UK; QStar XL; MDS SCIEX, Concord, Canada). MS ${ }^{2}$ experiments were carried out in the usual fashion by mass selecting the $\mathrm{MH}_{2}^{+2}$ ions with the quadrupole mass analyzer $\mathrm{Q}$ with CID in the quadrupole collision cell $\mathrm{q}$ and mass analysis of the ionic products with time-of-flight analyzer. By varying the collision voltage in the quadrupole cell breakdown graphs, expressing, in a qualitative way, the energy dependences of the fragmentation reactions were obtained under multiple collision conditions. In the quasi-MS ${ }^{3}$ experiments, CID in the interface region produced fragment ions with those of interest being mass-selected by the quadrupole mass analyzer $Q$ for fragmentation and analysis in the usual way.

Ionization was by electrospray on both instruments with the peptide sample, at micromolar concentration, dissolved in 1:1 $\mathrm{CH}_{3} \mathrm{OH}: 1 \%$ aqueous formic acid, and introduced into the ion source at a flow rate of $10 \mu \mathrm{L}$ $\min ^{-1}$. The electrospray capillary was held at about 3 $\mathrm{kV}$. In the Ultima III nitrogen was used as nebulizing and drying gas whereas argon was used as collision gas in the quadrupole cell. For the QStar nitrogen was used as nebulizing and drying gas as well as for collision gas in the quadrupole cell. There is no provision for measuring the collision gas pressure on either instrument; with the collision gas flowing the pressure gauge for the quadrupole region read $\sim 5 \times 10^{-5}$ mbar. Very comparable results were obtained on the two instruments.

Typically, fifty 1s scans were accumulated by the data system. The peak centering program allows one to obtain ion signals in terms of relative peak heights or relative peak areas. In terms of relative peak heights the signals for the complementary $\mathrm{b}$ and $\mathrm{y}$ ions formed by charge separation were approximately the same. However, in terms of relative peak areas the signal for the $y$ ion was more intense than that for the complementary $b$ ion, reflecting broader peaks for the high mass $y$ ions than the lower mass $b$ ions. (In CID of singlyprotonated species, peak areas and peak heights gave very comparable results.) The results presented in the following represent relative peak areas.

The $(\text { Ala })_{X}$ His peptides were obtained from Celtek Peptides (Nashville, TN, USA) while trialanine and cyclo(-Ala-Ala) were received from Bachem Biosciences (King of Prussia, PA, USA). No impurities were detected in the mass spectra of the peptides and they were used as received.

\section{Results and Discussion}

Peptides of the sequence (Ala) $)_{x}$ His were found to form abundant doubly-protonated species in electrospray ionization; these doubly-protonated species were found to fragment primarily by amide bond cleavage and charge separation. Paizs and coworkers [13] have recently carried out a detailed computational and experimental study of the fragmentation of doubly-protonated (Gly) $)_{5} \mathrm{Arg}$. They concluded that the fragmenting species passing the amide bond cleavage transition-state formed initially a symmetric doubly-protonated dimer (DPD) where each fragment is protonated (s-DPD). Within this dimer proton transfer can occur from the N-terminal fragment to the C-terminal fragment resulting in an asymmetric doubly-protonated dimer (a-DPD). The latter may dissociate in a barrier free process (i.e., no reverse energy barrier) to form a doubly-protonated C-terminal fragment. On the other hand the s-DPD dissociates over a barrier to form singly-protonated $\mathrm{N}$ - and C-terminal fragments. The barrier reflects the activation barrier for the reverse reaction arising primarily from coulombic repulsion as the two charged fragments are brought together. This model adequately rationalizes the results obtained in the present study.

Figure 1 presents representative CID mass spectra for the five doubly-protonated peptides studied. In all cases the dominant fragmentation involves symmetrical amide bond cleavage to form the complementary $b_{m}$ and $\mathrm{y}_{\mathrm{N}-\mathrm{m}}$ ions ( $N=$ total number of amino acid residues). Thus, for example, for (Ala) ${ }_{6}$ His one observes the $\mathrm{y}_{5}$ ion and the complementary $\mathrm{b}_{2}$ ion, among other pairs. When symmetrical cleavage of the $\mathrm{N}$-terminal amide bond occurs presumably the $b_{1}$ ion is formed. In general, $b_{1}$ ions are unstable $[14,15]$ and lose $\mathrm{CO}$ to form, in this case, the alanine iminium ion at $m / z 44$. When scanning over a wide mass range the sensitivity for low mass ions is low; as a result the weak alanine iminium ion signal was not recorded.

A minor fragmentation route involves asymmetric cleavage of the amide bond to form a lower mass doubly-protonated $\mathrm{y}$ ion and a corresponding neutral. In all cases these asymmetric amide bond cleavages occur near the N-terminus of the peptide. Thus, (Ala) ${ }_{5}$ His shows a weak signal for $\mathrm{y}_{5}^{+2},(\mathrm{Ala})_{6}$ His shows weak signals for $\mathrm{y}_{5}^{+2}$ and $\mathrm{y}_{6}^{+2},(\mathrm{Ala})_{7}$ His shows weak signals for $\mathrm{y}_{6}^{+2}$ and $\mathrm{y}_{7}^{+2},(\mathrm{Ala})_{8}$ His shows weak signals for $\mathrm{y}_{7}^{+2}$ and $\mathrm{y}_{8}^{+2}$ while (Ala) ${ }_{10}$ His shows a signal for $\mathrm{y}_{9}^{+2}$ and a very weak signal at $m / z 398$ corresponding to $\mathrm{y}_{10}^{+2}$.

The primary $b$ and $y$ ions undergo further fragmentation, particularly at higher collision energies. Figure 2 shows the breakdown graph for the $\mathrm{MH}_{2}^{+2}$ ion of (Ala) ${ }_{6}$ His. From the shapes of the relevant plots it is evident that $\mathrm{y}_{1}, \mathrm{y}_{2}, \mathrm{a}_{2}$, and $\mathrm{a}_{3}{ }^{*}$ are secondary products. Figure 3 shows a CID mass spectrum for singlyprotonated (Ala) ${ }_{6}$ His. A complex spectrum results with $\mathrm{y}_{1}$ and $\mathrm{y}_{2}$ ions being major fragmentation products along with significant yields for $b_{5}$ and $b_{6}$. The $b$ ions are known to fragment further to give a ions $[15,16]$ 
with the exception of the $b_{3}$ ion which does not form a stable $a_{3}$ ion but rather produces the $a_{3}{ }^{*}\left(a_{3}-N_{3}\right)$ ion $[17,18]$. These fragmentation reactions are evident from the plots of Figure 1.

From the relative abundances of the primary y and $b$ ions formed by charge separation, one can obtain rough estimates of the fraction of total symmetric amide bond cleavage for each amide bond. The results of these calculations are shown in Figure 4. The results showed little variation with collision energy at the lower collision energies which were used to derive the data of
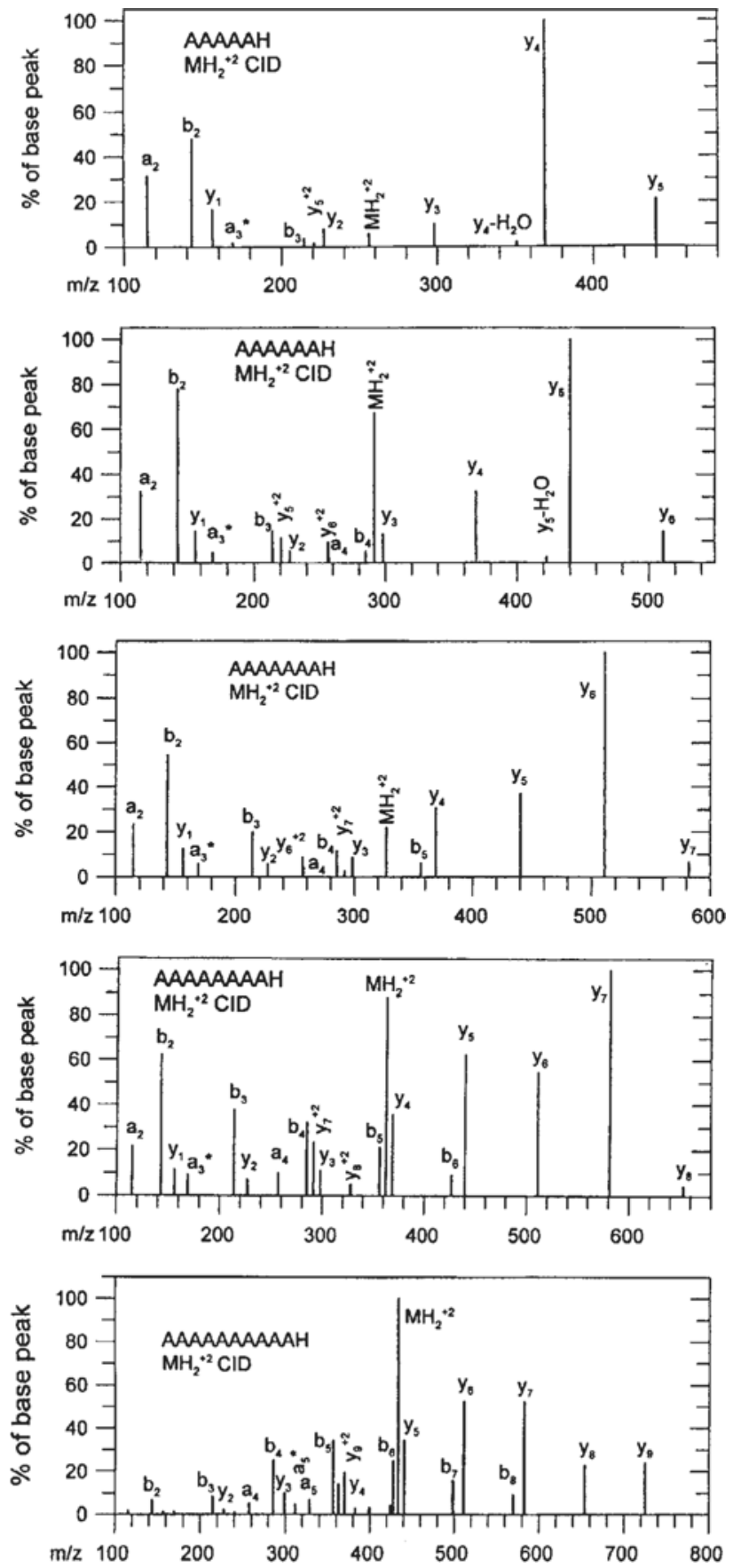

Figure 1. CID mass spectra of doubly-protonated (Ala) $)_{x}$ His peptides. $20 \pm 2 \mathrm{eV}$ collision energy.

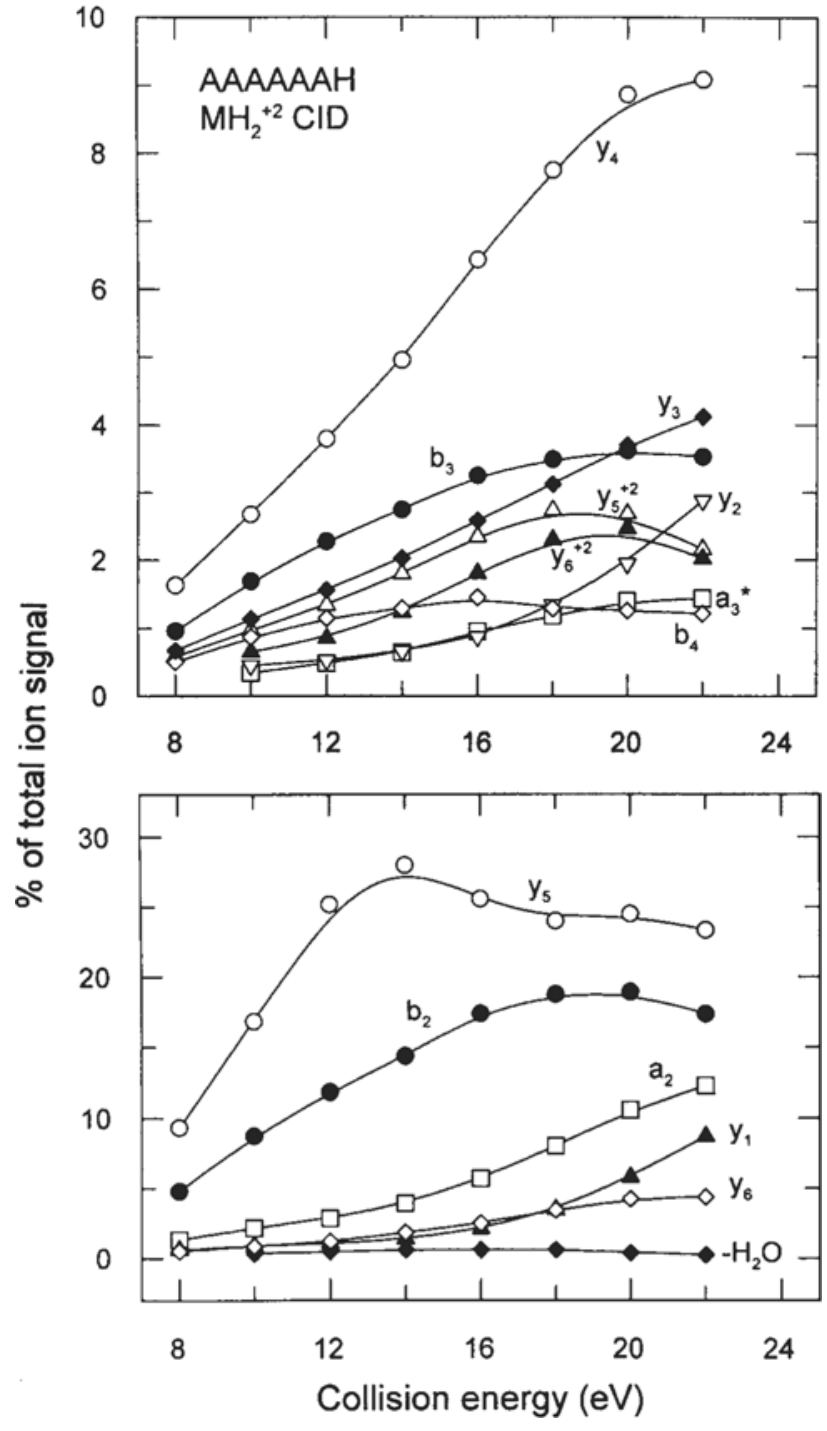

Figure 2. Breakdown graph for doubly-protonated (Ala) ${ }_{6}$ His.

Figure 4 and Figure 5. One notes that there is relatively satisfactory agreement of the relative probabilities of symmetric amide bond cleavage calculated from the relative $y$ ion intensities and the relative $b$ ion intensi-

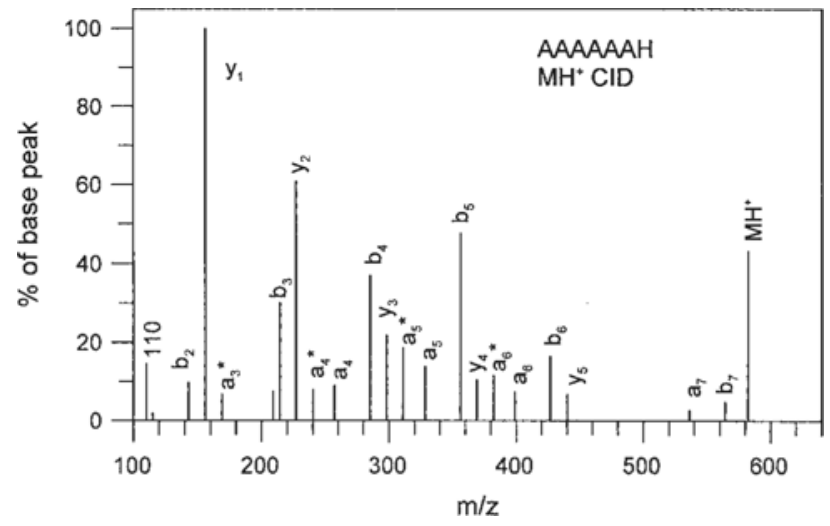

Figure 3. CID mass spectrum for singly-protonated (Ala) ${ }_{6}$ His. 


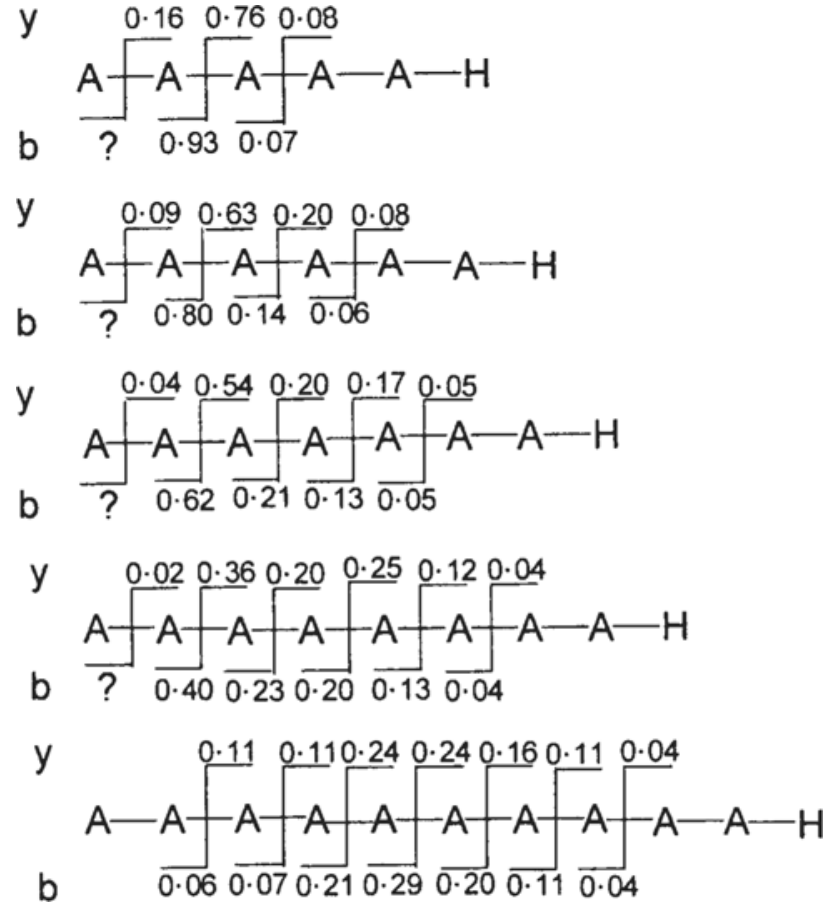

Figure 4. Fractional symmetric amide bond cleavage derived from relative $y$ ion and relative $b$ ion signals.

ties. In agreement with the analysis of Zubarev and coworkers [11] symmetric cleavage of the second amide bond dominates for smaller peptides but decreases substantially in importance as the peptide size increases and is not the dominant cleavage mode for doublyprotonated (Ala) ${ }_{10}$ His. Paizs and coworkers [13] also observed that symmetric cleavage of the second amide bond was the dominant fragmentation mode for doublyprotonated $(\mathrm{Gly})_{5} \mathrm{Arg}$. The probability of symmetric cleavage of the first amide bond, while significant for (Ala) $)_{5} \mathrm{His}$, decreases with increasing size of the peptide and is not observed for doubly-protonated (Ala) ${ }_{10}$ His. The smallest $y$ ion observed as a primary product is the $\mathrm{y}_{3}$ ion with the complementary $\mathrm{b}$ ion also observed in each case; these products, observed in low yield, represent symmetric cleavage of the third amide bond from the C-terminus.

As Figure 3 shows, the larger $y$ ions formed by charge separation can fragment further to form high mass $b$ ions. Thus, apparently the relative $y$ ion abundances provide the best measure of the relative probabilities of symmetric amide bond cleavage. The results obtained in this way are plotted in bar-graph form in Figure 5 for the three largest peptides studied. In the nomenclature of Zubarev and coworkers [11], doublyprotonated $(\mathrm{Ala})_{7} \mathrm{His}$ and the smaller peptides are clearly examples of Class I peptides in that cleavage of the second amide to form $b_{2}$ and $y_{N-2}$ is the dominant symmetric amide bond cleavage reaction. On the other hand, doubly-protonated (Ala) ${ }_{10} \mathrm{His}$ is an example of a Class II peptide in showing symmetric cleavage of the fourth and fifth bonds as the most probable cleavage reactions. Yet even here the cleavage of the second amide bond appears to be greater than one might expect for a smooth distribution of fractional yields. (It also is noted that the yield of the $\mathrm{y}_{9}^{+2}$ arising by asymmetric cleavage of amide bond two is circa $56 \%$ of the $\mathrm{y}_{9}$ yield. If this asymmetric fragmentation is included clearly there still is enhanced reactivity of the second amide bond.) Doubly-protonated (Ala) ${ }_{8}$ His appears to be a transitional (bifurcating) case in which both the second and the fourth amide bonds show enhanced reactivity in charge separation reactions. As Figure 6 shows, this is evident over the entire collision energy range studied, i.e., $\mathrm{y}_{7}$ and $\mathrm{y}_{5}$ are more abundant than $\mathrm{y}_{6}$.

We also have examined the structure of the $b_{2}$ ion formed by charge separation in doubly-protonated
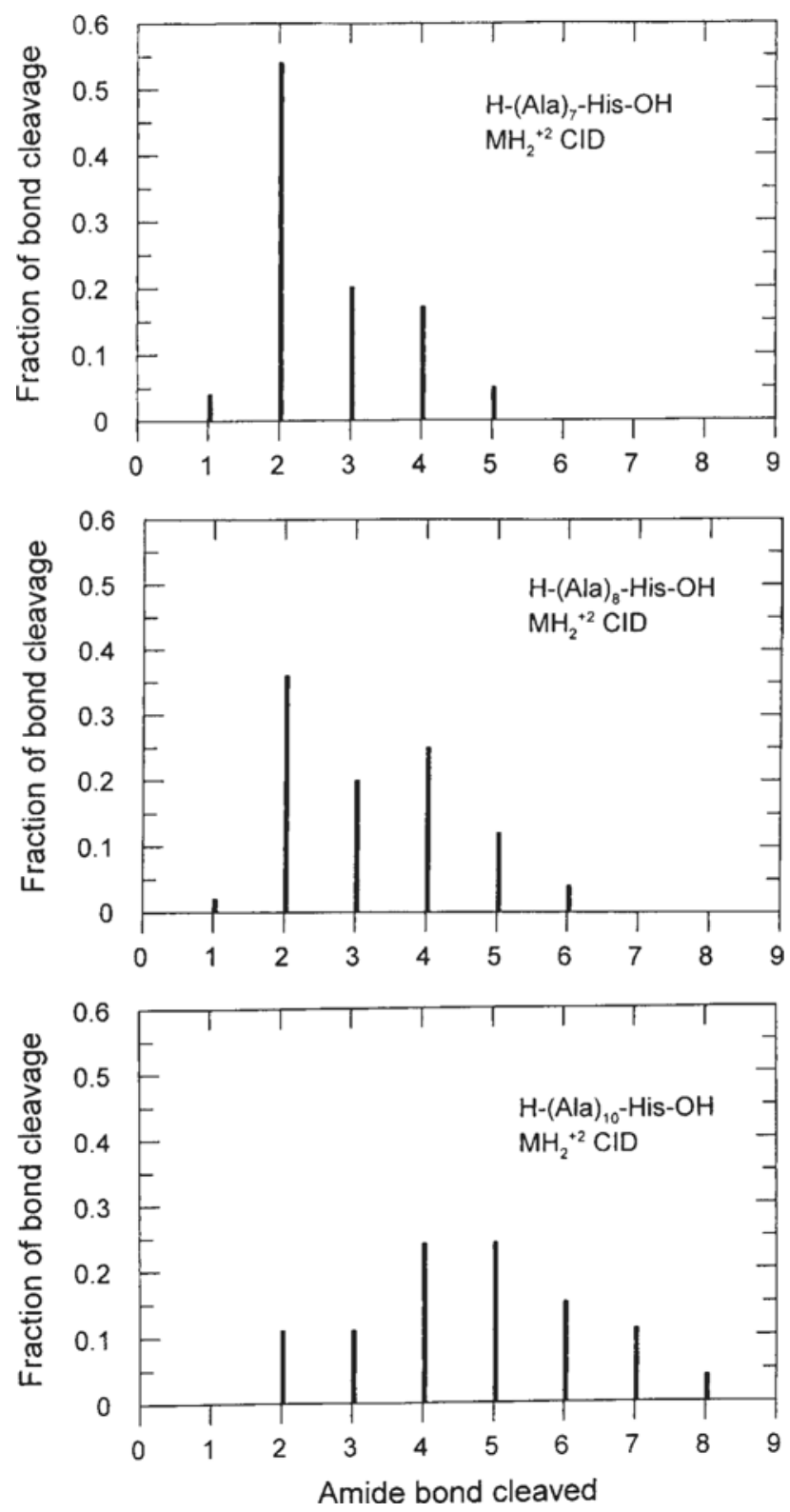

Figure 5. Fractional symmetric amide bond cleavage derived from relative y ion signals only. 


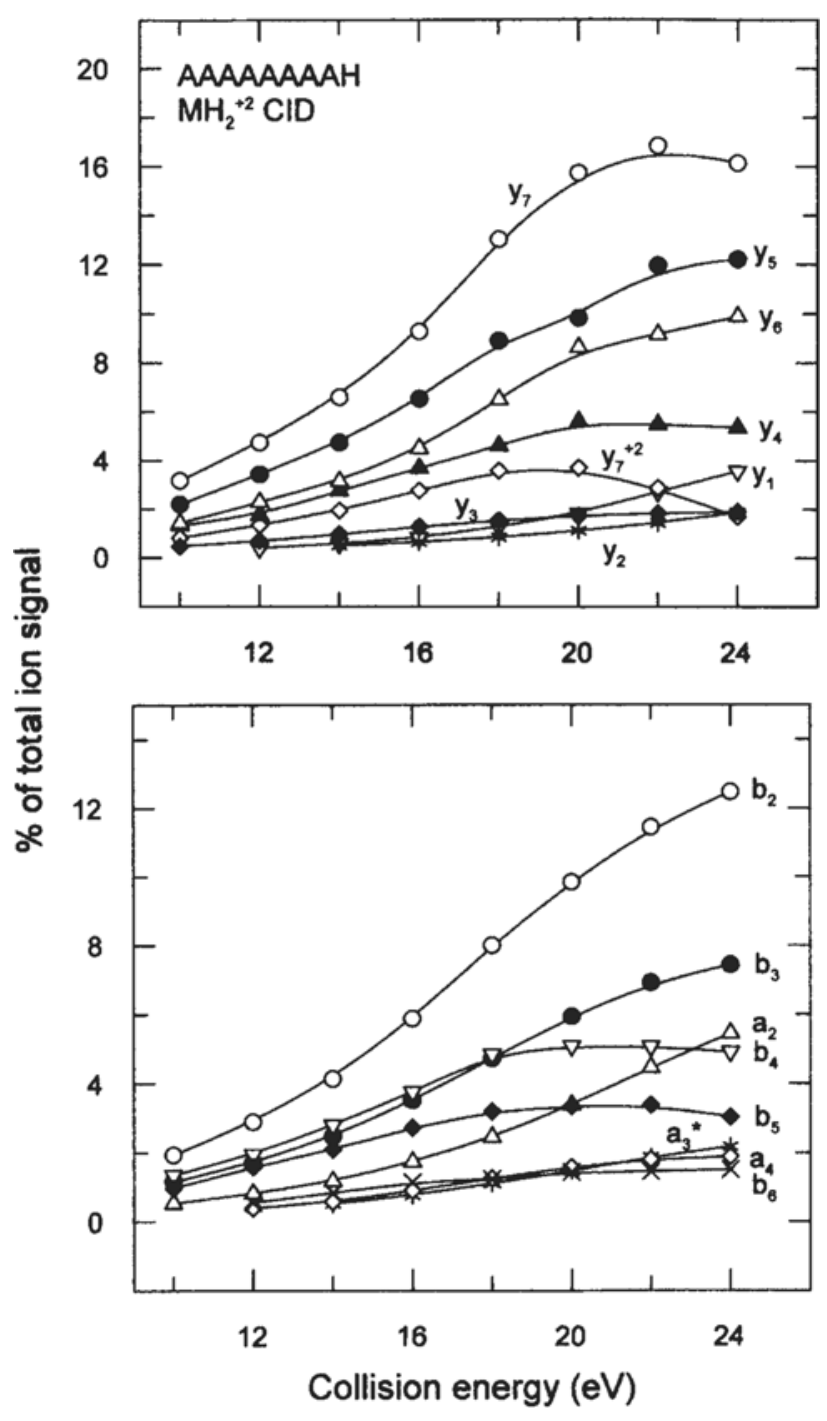

Figure 6. Breakdown graph for doubly-protonated (Ala) ${ }_{8}$ His.

(Ala) $)_{5} \mathrm{His}$, an example of a Class I peptide in the nomenclature of Zubarev and coworkers [11]. Table 1 presents the CID mass spectrum of the $b_{2}$ ion and compares that with the spectrum of protonated cyclo(Ala-Ala) and with that of the $\mathrm{b}_{2}$ ion derived by fragmentation of protonated trialanine. Oomens et al. [19] have recently shown by infrared multiphoton dissociation (IRMPD) that the latter $b_{2}$ ion has an oxazolone structure protonated at the oxazolone $\mathrm{N}$-atom.
The CID mass spectrum of the $b_{2}$ ion derived from doubly-protonated $(\mathrm{Ala})_{5} \mathrm{His}$ is in good agreement with the spectrum of the $b_{2}$ ion derived from trialanine, which, as discussed above, is known to have an oxazolone structure. Since both these spectra represent quasi-MS ${ }^{3}$ studies under identical conditions the results provide very strong evidence that the $b_{2}$ ion formed by charge separation in doubly-protonated (Ala) $)_{5}$ His has a protonated oxazolone structure. The CID mass spectrum of protonated cyclo(Ala-Ala) is quite different, providing further support that the $b_{2}$ ion from the doubly-protonated peptide does not have a protonated diketopiperazine structure.

Zubarev and coworkers [11] proposed that the dominant formation of $\mathrm{y}_{\mathrm{N}-2}$ ions in Class I peptides was the result of concurrent formation of $b_{2}$ ions with a protonated diketopiperazine structure rather than the more common protonated oxazolone structure $[15,20]$. However, it is not clear from their publication that this postulate necessarily applies to the case where the first two residues are Ala, since the propensity for cleavage of the second amide bond was rather low in these cases. However, it should be noted that recent studies [21, 22] have cast some doubt concerning the formation of a diketopiperazine structure for tryptic peptides not containing Ala as the first two residues.

\section{Conclusions}

The present study shows that peptide chain length plays a significant role in the bifurcating nature of fragmentation of doubly-protonated peptides elucidated by the statistical analysis of Zubarev and coworkers [11]. The smaller peptides studied clearly belong to Class I in showing dominant cleavage of the second amide bond, while the largest peptide studied, (Ala) ${ }_{10} \mathrm{His}$, belongs to Class II in showing major cleavage at the fourth and fifth amide bonds. But even here, there appears to be a greater cleavage of the second amide bond than a smooth distribution would imply. Presumably, Coulombic repulsion influences how close the mobile proton can approach the fixed charge on the His side chain and, thus, will influence the amide bond cleaved in charge separation reactions. However, apparently other unearthed factors also may play a role. In addition to chain length, it is highly likely that individual residues in the chain will influence the amide bond

Table 1. CID of $\mathrm{m} / \mathrm{z} 143$ ions*

\begin{tabular}{|c|c|c|c|c|c|}
\hline$m / z$ & Ion & Neutrals lost & $\mathrm{A}_{5} \mathrm{H} \mathrm{b}_{2}$ & Сус $(\mathrm{A}-\mathrm{A}) \mathrm{MH}^{+}$ & AAA $b_{2}$ \\
\hline 143 & $\mathrm{C}_{6} \mathrm{H}_{11} \mathrm{~N}_{2} \mathrm{O}_{2}$ & & 27.91 & 68.29 & 13.86 \\
\hline 115 & $\mathrm{C}_{5} \mathrm{H}_{11} \mathrm{~N}_{2} \mathrm{O}$ & $\mathrm{CO}$ & 100 & 9.76 & 100 \\
\hline 98 & $\mathrm{C}_{5} \mathrm{H}_{8} \mathrm{NO}$ & $\mathrm{CO}+\mathrm{NH}_{3}$ & & 42.18 & \\
\hline 87 & $\mathrm{C}_{4} \mathrm{H}_{11} \mathrm{~N}_{2}$ & $2 \mathrm{CO}$ & 7.79 & & 7.76 \\
\hline 72 & $\mathrm{C}_{3} \mathrm{H}_{6} \mathrm{NO}$ & $\mathrm{CO}+\mathrm{CH}_{3} \mathrm{CH}=\mathrm{NH}$ & & 17.22 & \\
\hline 70 & $\mathrm{C}_{4} \mathrm{H}_{8} \mathrm{~N}$ & $2 \mathrm{CO}+\mathrm{NH}_{3}$ & & 9.42 & \\
\hline 44 & $\mathrm{C}_{2} \mathrm{H}_{6} \mathrm{~N}$ & $2 \mathrm{CO}+\mathrm{CH}_{3} \mathrm{CH}=\mathrm{NH}$ & 68.61 & 100 & 64.42 \\
\hline
\end{tabular}

${ }^{*}$ Collision energy $12 \mathrm{eV}$ for $\mathrm{b}_{2}$ ions and $16 \mathrm{eV}$ for cyclo(A-A)MH $\mathrm{MH}^{+}$ion. 
cleaved. In this respect, Wysocki and coworkers [23] have observed that doubly-protonated Val-Pro-AlaPro-Arg shows extensive cleavage at the N-terminal amide bond to form both $\mathrm{y}_{4}$ and $\mathrm{y}_{4}^{+2}$ ions with only minor cleavage of the second amide bond. They also observed that doubly-protonated Val-Pro-Asp-Pro-Arg showed major cleavage C-terminal to the Asp residue to give the complementary $b_{3}$ and $y_{2}$ ions by charge separation. Clearly, further studies of model systems are likely to prove informative.

\section{Acknowledgments}

The continued financial support of the Natural Sciences and Engineering Research Council (Canada) is greatly appreciated. Dr. B. Paizs is thanked for helpful discussions and for communication of results before publication.

\section{References}

1. Larsen, M. R.; Roepstorff, P. Mass Spectrometric Identification of Proteins and Characterization of their Post-Translational Modifications in Proteome Analysis. Fresenius J. Anal. Chem. 2000, 366, 677-690.

2. Aebersold, R.; Goodlett, D. R. Mass Spectrometry in Proteomics. Chem. Rev. 2001, 101, 269-295.

3. Medzihradszky, K. F. Peptide Sequence Analysis. Methods Enzymol. 2005, 402, 209-244.

4. Fenn, J. B.; Mann, M.; Meng, C. K.; Wang, S. F.; Whitehouse, C. M. Electrospray Ionization for Mass Spectrometry of Large Biomolecules. Science 1989, 246, 64-71.

5. Wysocki, V. H.; Tsaprailis, G.; Smith, L. L.; Breci, L. A. Mobile and Localized Protons. A Framework for Understanding Peptide Dissociation. J. Mass Spectrom. 2000, 35, 1399-1406.

6. Paizs, B.; Suhai, S. Fragmentation Pathways of Protonated Peptides. Mass Spectrom. Rev. 2005, 24, 508-548.

7. Vékey, K.; Candido, M.; Traldi, P. Use of Charge-Separation Reactions for Sequencing Peptides. Rapid Commun. Mass Spectrom. 1990, 4, 74-76.

8. Tang, X.; Boyd, R. K. An Investigation of Fragmentation of Doubly Protonated Tryptic Peptides. Rapid Commun. Mass Spectrom. 1992, 6, 651-657.
9. Tang, X.; Thibault, P.; Boyd, R. K. Fragmentation Reactions of MultiplyProtonated Peptides and Implications for Sequencing by Tandem Mass Spectrometry with Low-Energy Collision-Induced Dissociation. Anal. Chem. 1993, 65, 2824-2834.

10. Adams, J.; Strobel, F. H.; Reiter, A.; Sullards, M. C. The Importance of Charge-Separation Reactions in Tandem Mass Spectrometry of Doubly Protonated Angiotensin II Formed by Electrospray Ionization: Experimental Considerations and Structural Implications. J. Am. Soc. Mass Spectrom. 1996, 7, 30-41.

11. Savitski, M. M.; Fälth, M.; Fung, Y. M. E.; Adams, C. M.; Zubarev, R. A Bifurcating Fragmentation Behavior of Gas-Phase Tryptic Peptide Dications in Collisional Activation. J. Am. Soc. Mass Spectrom. 2008, 19, 1755-1763.

12. Bleiholder, C.; Suhai, S.; Paizs, B. Revising the Proton Affinity Scale of the Naturally Occurring $\alpha$-Amino Acids. J. Am. Soc. Mass Spectrom. 2006, $17,1275-1281$.

13. Bleiholder, C.; Suhai, S.; Somogyi, Á.; Paizs, B. Fragmentation Pathways of Doubly-Protonated Tryptic Peptides. J. Am. Soc. Mass Spectrom., unpublished.

14. Tsang, C. W.; Harrison, A. G. Chemical Ionization of Amino Acids J. Am. Chem. Soc. 1976, 98, 1301-1308.

15. Yalcin, T; Khouw, C.; Csizmadia, I. G.; Peterson, M. R.; Harrison, A. G. Why Are B Ions Stable Species in Peptide Mass Spectra ?. J. Am. Soc. Mass Spectrom. 1995, 6, 1165-1174.

16. Harrison, A. G.; Young, A. B. Fragmentation of Protonated Oligoalanines. Amide Bond Cleavage and Beyond. J. Am. Soc. Mass Spectrom. 2004, 15, 1810-1819.

17. Cooper, T.; Talaty, E.; Grove, J.; Van Stipdonk, M.; Suhai, S.; Paizs, B. Isotope Labeling and Theoretical Study of the Formation of $\mathrm{a}_{3}{ }^{*}$ Ions from Protonated Tetraglycine. J. Am. Soc. Mass Spectrom. 2006, 17, $1654-1664$.

18. Allen, J. M.; Racine, A. H.; Berman, A. M.; Johnson, J. S.; Bythell, B. J.; Paizs, B.; Glish, G. L. Why are $\mathrm{a}_{3}$ Ions Rarely Observed? J. Am. Soc. Mass Spectrom. 2008, 19, 1764-1770.

19. Oomens, J.; Young, S.; Molesworth, S.; Van Stipdonk, M. Spectroscopic Evidence for an Oxazolone Structure of the $b_{2}$ Fragment Ion from Protonated Tri-Alanine. J. Am. Soc. Mass Spectrom. 2009, 20, 334-339.

20. Nold, M. J.; Wesdemiotis, C.; Yalcin, T.; Harrison, A. G. Amide Bond Dissociation in Protonated Peptides. Structures of the N-Terminal Ionic and Neutral Fragments. Int. J. Mass Spectrom. Ion Processes 1997, 164, 137-153.

21. Bythell, B. J.; Somogyi, Á.; Paizs, B. What is the Structure of $b_{2}$ Ions Generated from Doubly Protonated Tryptic Peptides? J. Am. Soc. Mass Spectrom. 2009, 20, 618-624.

22. Bythell, B. J.; Erlekam, U.; Paizs, B.; Maître, P. Infrared Spectroscopy of Fragments from Doubly Protonated Tryptic Peptides. Chem. Phys. Chem. 2009, 10, 883-885.

23. Smith, L. L.; Herrmann, K. A.; Wysocki, V. H. Investigation of the Gas Phase Ion Structure for Proline-Containing $\mathrm{b}_{2}$ Ions. J. Am. Soc. Mass Spectrom. 2006, 17, 20-28. 